60th anniversary of Thorax

\section{Thorax 1991-1996}

\section{S G Spiro}

$\mathrm{T}$ he only bound volumes that I have of Thorax (five in all) were the annual collations of published papers during my tenure as Editor. I noted with some satisfaction that the pagination had risen from 939 pages in 1991 to 1328 pages by 1995.

For me, my short editorial announcing that we had agreed to publish Supplements to be produced with-but not integral to-Thorax was a huge leap forward. No, we may not have been pioneers here, but it represented a broadening of the content and it became a vehicle for Society guidelines, symposia summaries, and topical reviews.

The first supplement was the Guidelines for the Management of Asthma (1993;48:S1-24). Not only was this publication a great success, reaching a world audience and excellent for the journal's impact factor, it was also a considerable financial success as the pharmaceutical industry bought thousands of copies. These

\section{Thorax 1996-2002}

\section{A Knox, J Britton}

profits were in part transformed into more pages as I adopted a policy of expanding Thorax with papers of general interest, perhaps at the expense of the impact factor-always a controversial issue.

I think that, overall, the supplements raised the journal's profile. Other guideline supplements followed, some more successful than others. They have always been independently produced without sponsorship, although industry has often bought copies after publication. While they remain individual gambles, I was pleased to have added supplements to the content of Thorax.

Editor, 1991-1996

Thorax 2006;61:1020.

doi: 10.1136/thx.2006.072694

Correspondence to: Professor S G Spiro, Department of Thoracic Medicine, University College Hospital, London WC1E 6AU, UK; stephen.spiro@uclh.org

British Thoracic Society that guidelines written by them would automatically be published in the journal, irrespective of quality. These were interesting times.

Initially our policy resulted in a few lean issues of the journal but-lo and behold-as the impact factor of the journal rose, its perception did also and submissions increased steadily. Our ideas had been vindicated. Like Clinton in 1996, we stayed on for an extended term but all good things eventually come to a natural conclusion.

There were the issues of potential scientific misconduct, duplicate publications, ghost writing, etc. The former were often spotted by sharp eyed reviewers. These were inevitably a source of embarrassment to those involved and unnecessary hassle for us.

We were able to publish a number of papers which took respiratory medicine forward in new directions (and probably some which set it back!). Some examples of the former in common respiratory conditions were landmark papers highlighting the relationship between exacerbations and decline in lung function in $\mathrm{COPD}^{1}$ and papers characterising new phenotypes in asthma. ${ }^{2}$ There were also clinical papers with therapeutic implications in a diverse range of therapeutic areas such as a study defining the role of CPAP in mild sleep apnoea, ${ }^{3}$ a paper on bisphosphonates in treating osteoporosis in cystic fibrosis, ${ }^{4}$ and the occasional interesting anecdotal report such as a paper suggesting that GM-CSF was a novel treatment for alveolar proteinosis. ${ }^{5}$ On a more experimental note, laboratory studies suggested a potential for anti-TGF $\beta$ strategies in pulmonary fibrosis. ${ }^{6}$ These 